\title{
ANN Modelling of Propane-Powered 4-Stroke Spark Ignition Engine
}

\author{
Jehad A. A. Yamin ${ }^{1}$ \\ ${ }^{1}$ Mechanical Engineering Department, School of Engineering, The University of Jordan, Amman, Jordan \\ Correspondence: Jehad Yamin, Mechanical Engineering Department, School of Engineering, The University of \\ Jordan, Amman 11942, Jordan. Tel: 962-799-609-750. E-mail: yamin@ju.edu.jo
}

Received: August 8, 2017

Accepted: August 16, 2017

Online Published: September 9, 2017

doi:10.5539/mas.v11n10p1

URL: https://doi.org/10.5539/mas.v11n10p1

\begin{abstract}
An ANN model was developed by the authors and tested against experimental data available for an engine as supplied in the manual by the manufacturers. The model was found to perform excellently well by showing similar trends of performance for this engine as well as other engines for which the necessary data was available. This model was then used to perform some parametric studies to improve the performance of an engine using LPG (mainly Propane C3H8) as a fuel. This paper presents discussion on some of the parameters that affect the engine's thermal efficiency with suggestions to improve it. The effect of equivalence ratio, compression ratio and spark plug location at different speeds on the thermal efficiency have been studied. Based on the engine and the range of variables studied it was found that the best spark plug location was 0.395 for all equivalence ratios studied at $\mathrm{CR}=9$.
\end{abstract}

Keywords: Engine Simulation, LPG, propane, thermal efficiency

\section{Introduction}

Thermal efficiency can be understood to represent an indication as to how effectively the engine is utilizing the energy content of the fresh charge for the development of the power. In other words, how much of the fuel is taking active part in the combustion process and development of power. The increasing cost of liquid hydrocarbon fuels in the resent years accompanied by the stringent pollution rules and regulations has stimulated the interest in alternative fuels for automotive engines. One of the alternatives proposed to replace gasoline on the short term is Propane. Several methods were tested to improve the performance of LPG-powered, 4-stroke spark ignition engines.

The addition of coconut oil (Kapilan et.al, 2003), gasoline (Liu et.al, 2013), ethanol (Deng et.al, 2003), dimethyle ether (Wang and Bian, 2005) and many other supplements to LPG were studied. Each one of these supplements showed certain percentage of improvement. However, the idea of supplement fuel is not favorable since it is sometimes accompanied with additional accessories and equipment for the additional fuel. Another approach was the use of electronic fuel injection system (Li et.al, 2012), electronically-controlled LPG supplied unit (Komota and Inoue, 2005), methods to control the injection and ignition timing (Tsuruya et.al, 2004), closed-loop air/fuel ratio control with electronic engine management (Branner et.al, 1999), development of a totally new engine based on LPG properties to improve its low temperature and idling stability (Takeda and Matsubara, 1997), the use of fuel controllers to detect and control the air/fuel ratio in the intake and setting the multistage adjustment ranges of air/fuel ratio for the theoretical value at idling (Asada and Okawa, 2002), determination of the most suitable LPG formulation ratio i.e. propane to butane ratios) which was found to be in the range of $40-85 \%$ (Barkhordarioon et.al, 2001), the use under carburetor conditions (Sun et.al, 2002), varying the spark characteristics like energy and current/time profile (Abd-Alla et.al, 2003), the use of special evaporators (Price et.al, 2004), the use of stratified exhaust gas recirculation and lean burn to control the combustion process for improved combustion stability (Woo et.al, 004) and many other tested modifications were also investigated. Each one aimed at introducing improvement in one direction or parameter.

To assist these experimental researches, several theoretical studies investigated the performance of LPG as fuel for SI engines. (Bayraktar and Durgun, 2005) developed a quasi-dimensional spark ignition engine cycle model to predict the cycle performance and exhaust emission emissions of an automotive engine using gasoline and LPG fuels. (Yamin and Badran, 2002) developed a model to investigate the effect of heat loss on the engine performance with the aim of improving the engine performance with LPG fuel. (Wang et.al, 2001) also 
developed another thermodynamic model to study the mechanism of combustion and emission of both fuels i.e. gasoline and LPG. (Kim et.al, 1999) investigated the flame propagation characteristics, in a heavy-duty type LPG lean burn spark ignition engine, using a simulation model.

Many simulation models are now available to be used for studying the behavior of LPG as spark ignition engine fuel. Each one concentrates on certain phenomena. This is a brief review about the some of the research work conducted on LPG-powered spark ignition engines. Further, (Bayrakter and Durgun, 2005) investigated theoretically the effect of using LPG on the performance and emission of a 4-stroke, SI engine. He showed that using LPG can significantly improve the emission of the engine when operated at conditions similar to those of gasoline fuel.

Another line of attempt to improve the performance of propane-fueled SI engine was conducted by (Hackan and Yamin, 2008) in which they investigated the effect of variable stroke configuration on engine performance. Further, they (Yamin and Hackan, 2011) conducted second law analysis on propane-fueled engine.

This paper is an attempt to develop basic engine data relationships between the compression ratio, equivalence ratio, spark plug location, valve dimensions, exhaust pollutants and thermal efficiency of a light duty Spark Ignition Engine to optimize the engine for LPG properties. Then determine the potential for improving the Thermal Efficiency of the engine using this fuel.

\section{Propane as an S. I. Engine Fuel}

For any fuel to be considered as an alternative fuel, it has to fulfill certain criteria. The basic criterion for selecting any alternative is:

1. Availability: the fuel has to be in abundant supply or, preferably, derived from renewable sources.

2. High specific energy content.

3. Easy transportation and storage.

4. Minimum environmental pollution and resource depletion.

5. Good safety and handling properties.

Propane has proved its superiority over gasoline in most of these criteria. It can be noticed from Table (1) that with propane, the engine tends to operate at leaner mixtures making engine operation more economical. With higher calorific value, lower density and lower boiling point, propane used in vapor form causes engine operation and life to significantly improve with respect to gasoline.

Table 1. Properties of L.P.G and gasoline (Karim and Wierzba, 1984).

\begin{tabular}{lll}
\hline Characteristic & Propane & Gasoline \\
\hline Boiling Point $\left({ }^{\circ} \mathrm{C}\right)$ & -43 & $30-225$ \\
Molecular Mass $(\mathrm{kg} / \mathrm{Kmol})$ & 44.09 & 114.2 \\
Density of liquid at $15^{\circ} \mathrm{C}(\mathrm{kg} / \mathrm{l})$ & 0.508 & $0.73-0.78$ \\
Octane Number Research & 111 & $96-98$ \\
Measured & 97 & $85-87$ \\
Autoignition temperature $(\mathrm{K})$ & 740 & $501-744$ \\
Quenching gap in NTP air $(\mathrm{mm})$ & 1.78 & 2.0 \\
Maximum burning velocity in NTP air $(\mathrm{cm} / \mathrm{sec})$ & $37-40$ & $37-45$ \\
Flammability Limits in air $(\% \mathrm{vol}):$ Upper & 9.5 & 7.6 \\
Lower & 2.1 & 1.3 \\
\hline
\end{tabular}

Referring to the Table (1) above, it is noticed that Propane boils at temperatures far below those of gasoline. This means that it enters the inlet manifold in gaseous form, hence, when subjected to some of the exhaust heat, it causes little displacement to the incoming air hence reduced the mass of air that enters the engine cylinder.

This results in loss in thermal efficiency of the engine. Because of this loss of volumetric efficiency mainly due to high inlet temperature, engines tends to produce (3 - $5 \%$ ) lesser power than that of gasoline.

It was shown Heywood, 1989) that by offsetting the heat in the inlet manifold; a gain up to (8\%) in volumetric efficiency with respect to that of gasoline was achieved accompanied by an increase in engine power output levels to an equal bar with that of gasoline. 
From the engine performance parameters point of view; operation with propane reduces the brake specific fuel consumption (BSFC), however, since engines powered with Propane can work with higher compression ratios as a result of the higher Octane Number.

\section{Brief Description of the Model and Validation}

This program used is based on the theory developed by (Heywood, 1989; Benson, 1982; Blizard and Keck, 1974; Checkel and Dale, 1986), and is an extension of the work by (Yamin et.al, 2003 and Gupta et.al, 1995). This has been largely modified to cover a wide range of engines with the gas exchange process and turbulent combustion model included. A brief description of the model is shown in Appendix (A). The engine modeled and used for validation is the E6/T Ricardo Variable Compression Engine. Brief technical data of the engine is shown in Table (2).

Table 2. Engine design and operating conditions.

\begin{tabular}{ll}
\hline Engine speed & Variable \\
\hline Cylinder Bore & $7.62 \mathrm{~cm}$ \\
Stroke & $11.1125 \mathrm{~cm}$ \\
Connecting Rod Length & $23.335 \mathrm{~cm}$ \\
Displacement Volume & $506 \mathrm{~cm}^{3}$ \\
Compression Ratio & Variable \\
Intake Valve Diameter & $3.50 \mathrm{~cm}$ \\
Exhaust Valve Diameter & $3.005 \mathrm{~cm}$ \\
Ignition Timing & Variable \\
\hline
\end{tabular}

The results of the mathematical model were then verified against the experimental data of the engine as supplied by the manufacturer as shown in Figures (1-A \& 1-B). The figure shows that the results predicted by the mathematical model are very close within $(5 \%)$ to the experimental results. This verifies that the model developed can be used to a great degree of accuracy.

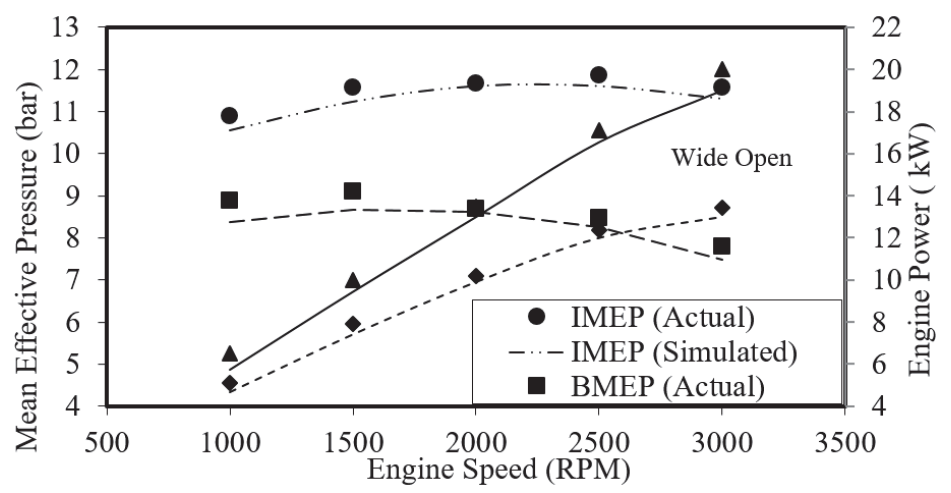

Figure (1-A). Results comparison between the calculated (model) and experimental

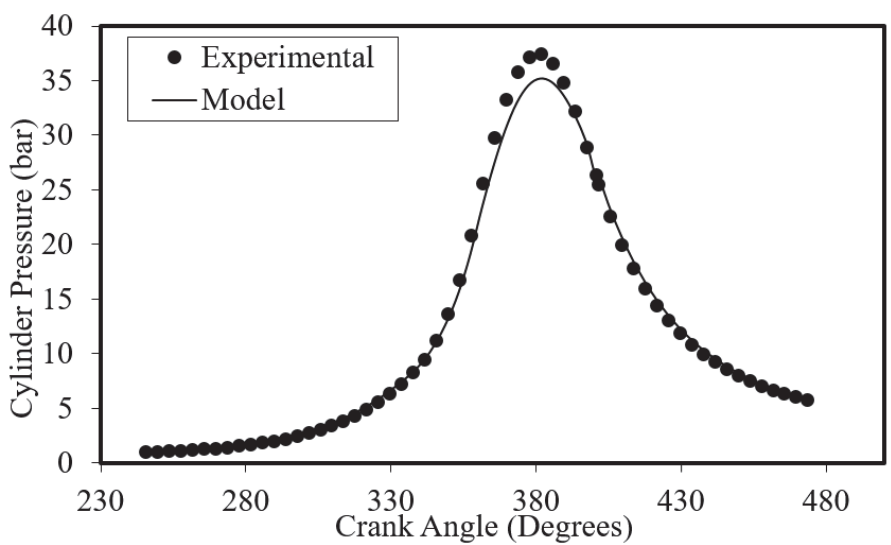

Figure (1-B). Pressure-Crank Angle diagram 


\section{Results and Discussion}

The efficiency of an engine defines the fraction of heat of combustion that ends up in useful mechanical power output. Present day S. I. Engines operate at efficiencies ranging between 10 to $30 \%$ depending primarily on air fuel ratio, compression ratio, engine speed, ignition timing and engine load condition. In addition to these operating variables, many other design features influence efficiency such as spark plug location, engine size, valve size, number of rings, number of cylinders. For a well-designed engine, operating variables greatly influence the engine efficiency. Further, the design and operating parameters also influence the concentration of pollutants emitted by the engine.

The parameters studied have been varied as follows:

1. Equivalence Ratio $(\lambda)$ has been varied from 0.7 to 1.2.

2. The Compression Ratio (CR) has been varied from 7.0 to 11.0.

3. The Spark Plug Location (XSP) has been varied from 0.08 to 0.5 .

4. Engine Speed (RPM) has been varied from 1000 to 3000 RPM.

5. Spark timing within $\pm 20^{\circ}$ from MBT.

6. Valve diameter from $3.0-5.0 \mathrm{~cm}$ and valve lift from $0.5-1.5 \mathrm{~cm}$.

7. The throttle conditions were set to wide-open throttle (WOT).

In the following section the effect of engine speed, compression ratio, equivalence ratio, spark plug location, spark timing and valve area, heat losses, flame speed and combustion duration on the, thermal efficiency have been discussed using propane as a fuel in S. I. Engines.

\subsection{Effect of Spark Timing and Equivalence Ratio on Thermal Efficiency}

Figure (2) shows the effect of the spark timing on the engine's thermal efficiency for different equivalence ratios. As seen from the graph that, at lean mixtures up to $\lambda=0.9$ the spark timing has to be advanced to achieve the best efficiency.

This is to allow for the slow combustion to be completed within TDC. At mixtures within stoichiometric, excess advancing and retarding beyond certain angle leads to reduction in thermal efficiency because spark retardation causes the combustion to be completed late in the power stroke.

Hence large quantity of fuel energy wasted with the exhaust gases, and excess advancing means early completion of combustion during which piston may still be moving towards the TDC causing power loss and allowing more time for the combustion products to lose heat to the surroundings.

On the other hand, excessive spark advance increases the knocking tendency (for all compression ratios) as shown in Figure (3). Hence in this study, the spark timing chosen for further study is $5^{\circ}-10^{\circ}$ retarded from MBT to suppress knocking. This angle is referred to as MBT in the next sections.

\subsection{Effect of Compression Ratio and Spark Plug Location}

Before starting to discuss the effect of these two factors, it would be proper to define a term used in describing the spark plug position i.e. 'XSP'. Spark plug position represents the ratio between the spark plug locations from the nearest wall to the cylinder diameter.

Figure (4) presents the effect of the compression ratio and spark plug location on the thermal efficiency. It is clearly seen that increasing the compression ratio increases the thermal efficiency due to increased expansion ratio and hence the work done during expansion is also increased causing improved thermal efficiency.

Further, increasing the compression ratio reduces the temperature of the exhaust gases causing lesser amounts of heat to be discharged with the exhaust. Moreover, shifting the spark from the edge to the center also improves the thermal efficiency as the flame speed is increased and hence combustion duration is reduced leading to lesser heat loss to the surroundings.

On the other hand, increasing both compression ratio and XSP increases the tendency to knock as shown in Figure (5) and emissions level (similar results were shown by (Tsuruya et.al, 2004 and Branner et.al, 1999)), therefore, increasing either of the factors has to be done with greater care. 


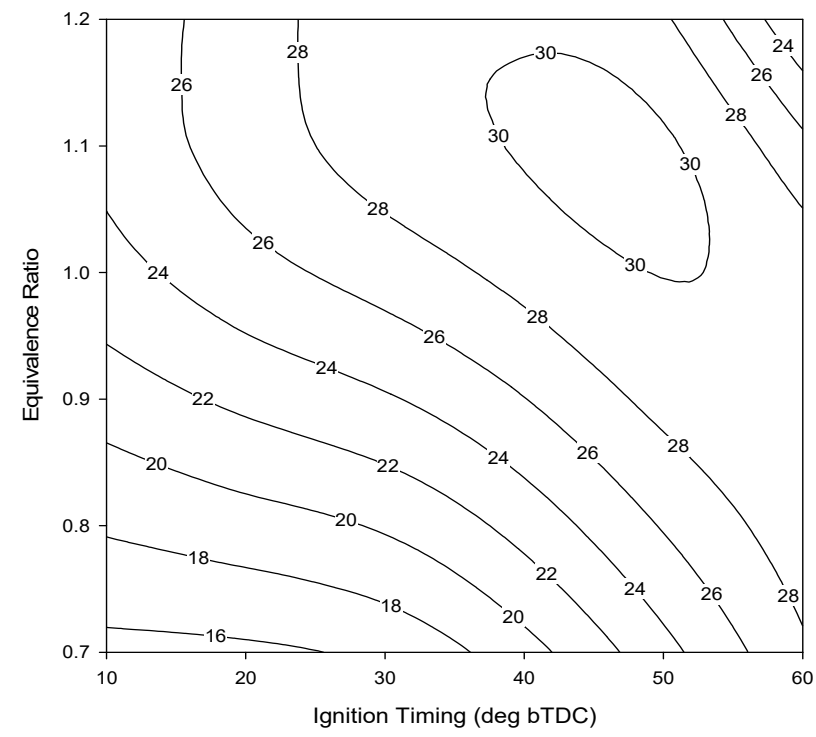

Figure 2. Effect of spark timing on thermal efficiency at different equivalence ratio

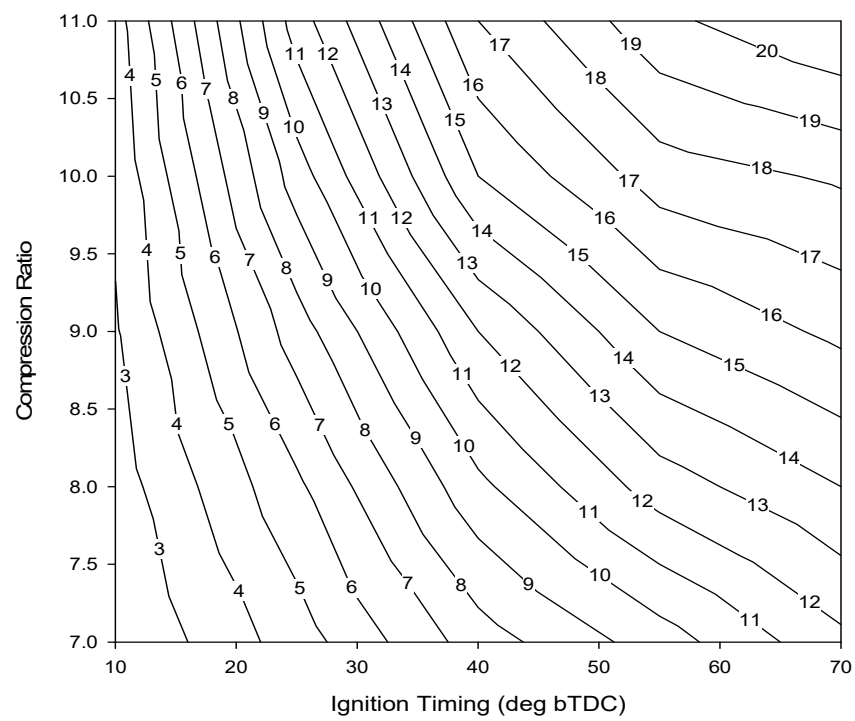

Figure 3. Effect of spark timing on the knocking tendency of the engine at different compression ratio

From the above discussion, XSP $=0.395$ has been chosen for the next study as it represents the best compromising position from knocking, power, fuel and emission point of view. Further, because most of the present day automobiles are designed with compression ratio $(C R)=9.0$, the next analysis shall be done with $\mathrm{CR}$ $=9.0$.

\subsection{Effect of engine speed and equivalence ratio $(\lambda)$}

Figure (6) shows the effect of engine RPM and equivalence ratio $(\lambda)$ on thermal efficiency. It is clearly seen that leaning the mixture increases the thermal efficiency because of the lesser dissociation and heat losses due to lower combustion temperature. As the fuel is enriched within stoichiometric, the dissociation and heat losses are increased leading to lower thermal efficiency.

At rich mixtures, the poor combustion is the main reason for the reduced thermal efficiency. Further seen that, as the engine RPM is increased the time available for the combustion to be completed is reduced causing lower thermal efficiency. 


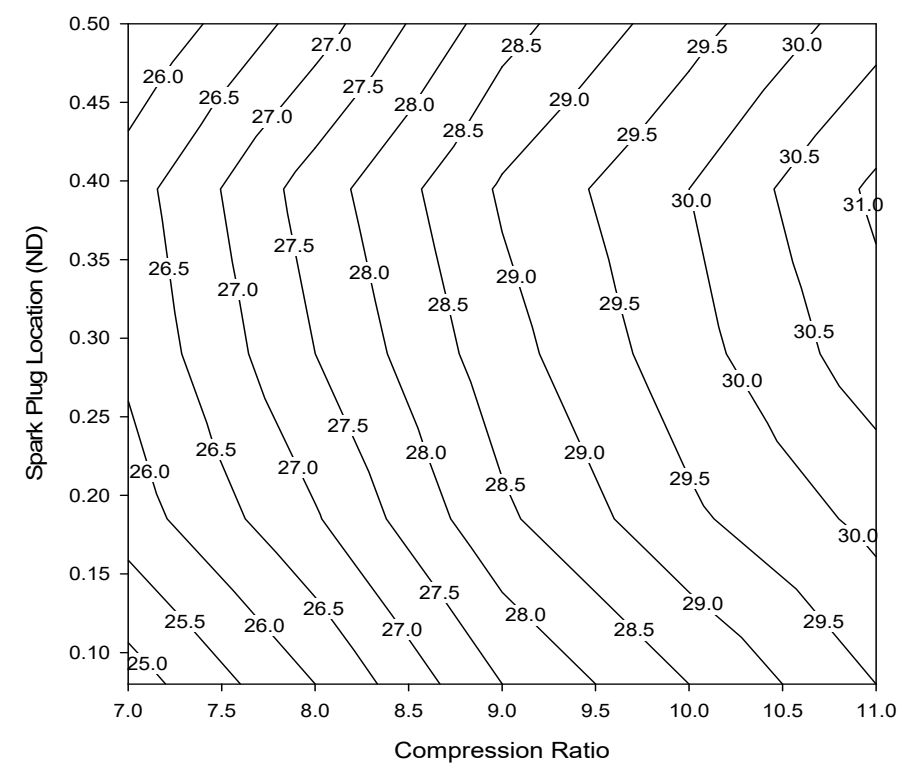

Figure 4. Effect of park plug location and compression ratio on thermal efficiency

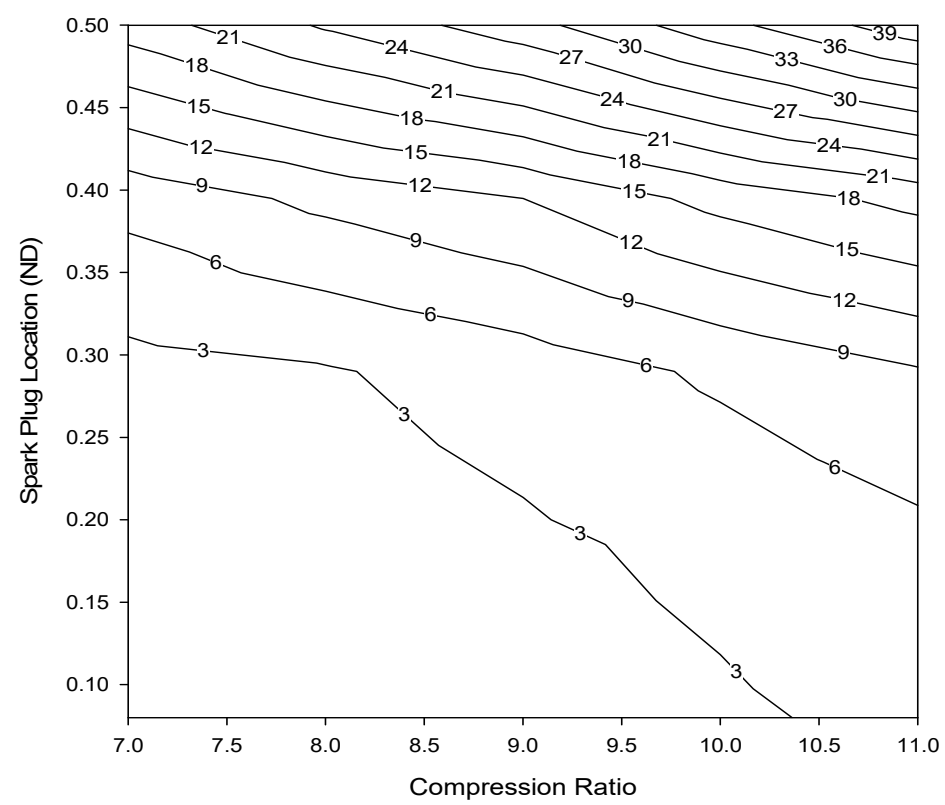

Figure 5. Effect of spark plug location and compression ratio on the knocking tendency of the engine

The advantage that LPG may run better with leaner mixtures with reduced greenhouse gases and hydrocarbons suggests that the present day carburetion systems has to work within this ratio $(\lambda=0.85-1.0)$ for good results.

\subsection{Effect of Inlet Valve Diameter and Lift}

Figure (7) shows the effect of inlet valve diameter and lift on the thermal efficiency. It can clearly been seen from the figure that increasing the valve area has a favorable effect on thermal efficiency. This is because of the availability of more fuel and oxygen to burn it at larger valve area, which means that more of the fuel heat energy is converted into useful work.

\subsection{Effect of Combustion Duration}

Figure (8) clearly shows that lengthening the combustion duration causes the thermal efficiency to drop because of the increased heat losses as the products of combustion would have more time to lose parts of its heat to the walls. Further, lengthening the duration of combustion would mean that the combustion would be completed late in the power stroke, which means that part of the heat liberated from the combustion of the fuel would be discharged along with the exhaust gases. On the other hand, shortening the combustion duration beyond certain 
time (5-7 mS) also leads to drop in engine efficiency due to non-availability of the time for the fuel to be fully burned, hence, more of the fuel is wasted with the exhaust unburned.

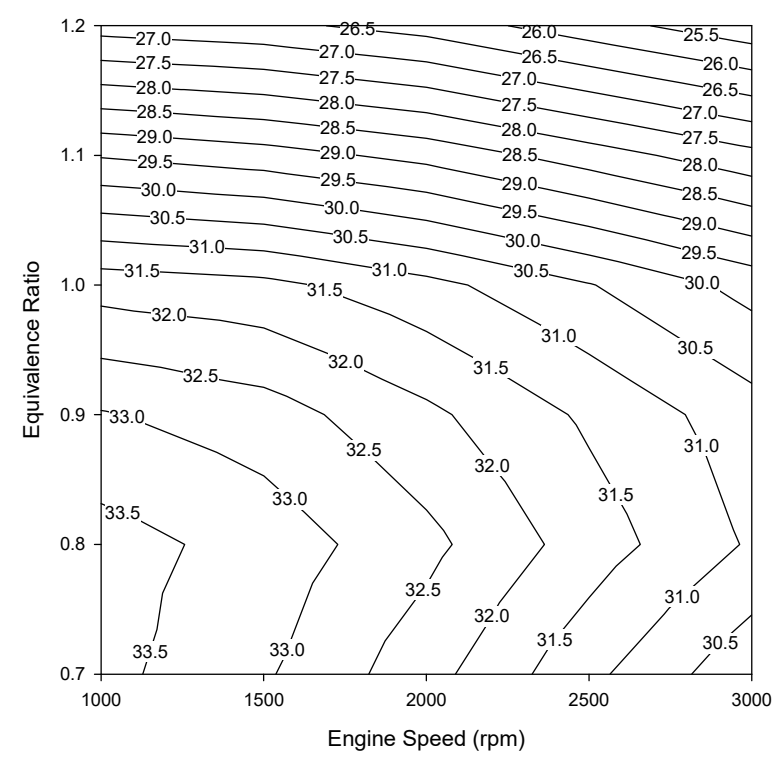

Figure 6. Effect of engine speed and equivalence ratio on thermal efficiency

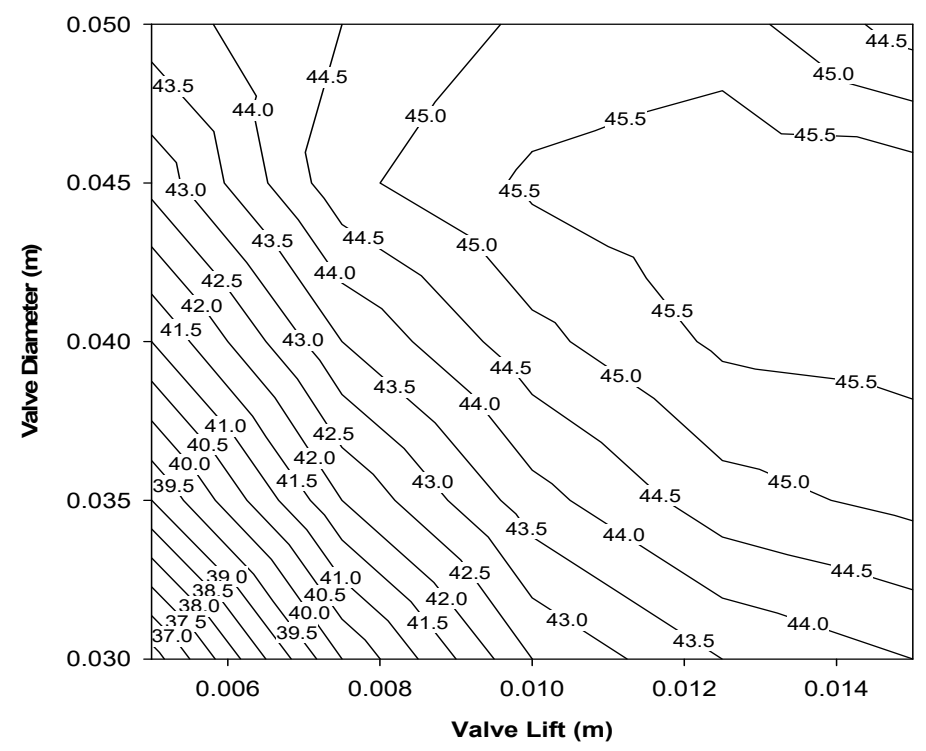

Figure 7. Effect of valve lift and diameter on thermal efficiency.

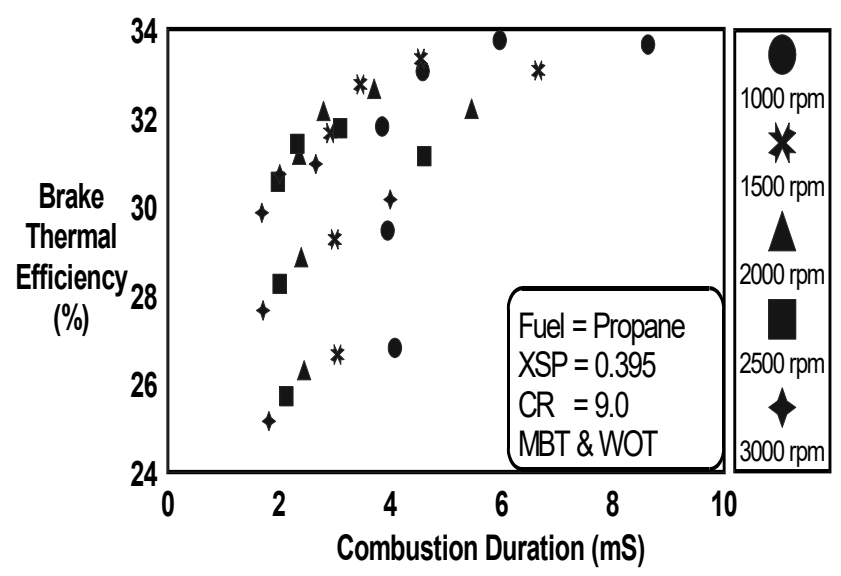

Figure 8. Effect of combustion duration on the thermal efficiency 
Now after discussing the effect of some design parameters on the engine's thermal efficiency, let us discuss the effect of thermal efficiency on some of the performance and emission parameters.

\subsection{Effect on Fuel Consumption}

The effect of thermal efficiency on fuel consumption is well established and documented in the literature. Figure (9) shows that the fuel consumption (represented by the brake specific fuel consumption) decreases as the thermal efficiency increases. This is in agreement with the results established in the literature.

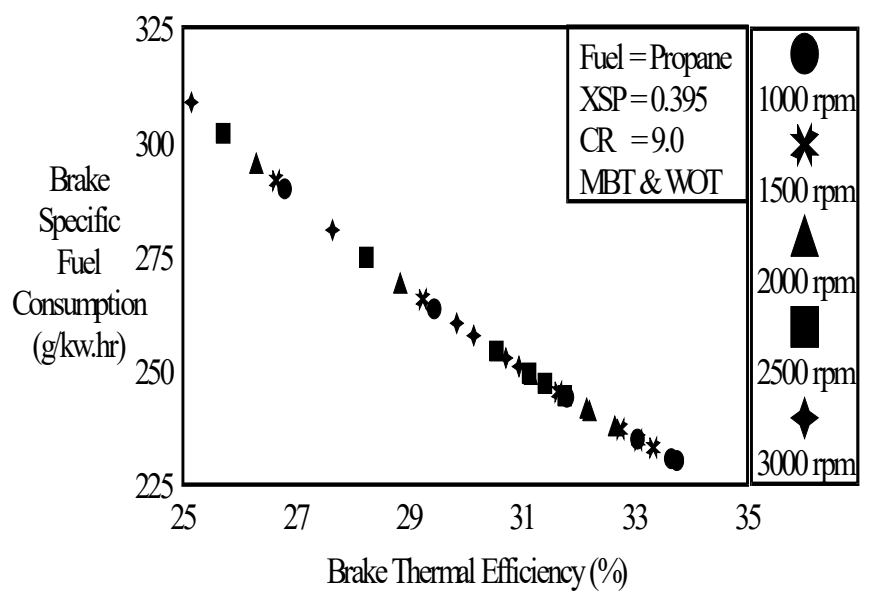

Figure 9. Effect of thermal efficiency on brake specific fuel consumption

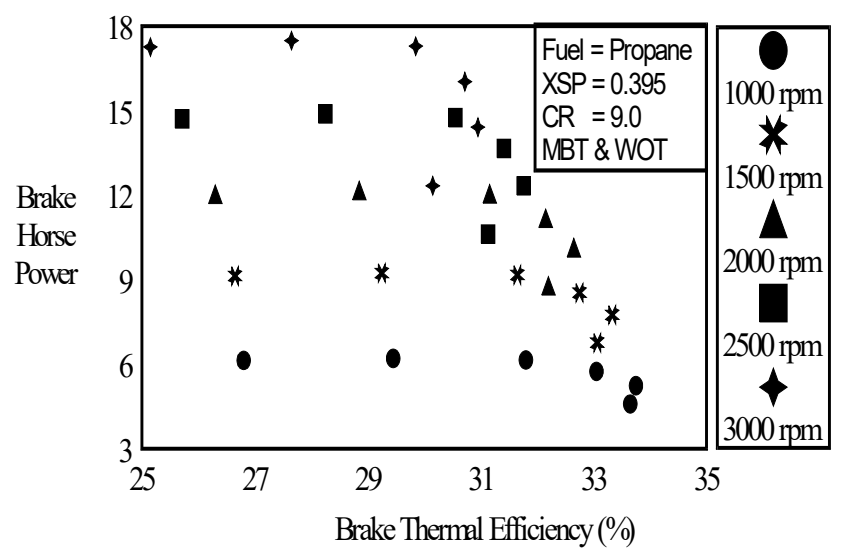

Figure 10. Effect of thermal efficiency on engine's brake horse power

\subsection{Effect on Engine Power}

As shown in Figure (10), increasing the thermal efficiency causes the engine power (represented by the brake horse power) to increase up to certain extent beyond that further increase causes power drop. This is expected to be due to the effect of dissociation and more heat losses as the cylinder temperature is increased.

\subsection{Effect on Carbon Monoxide (CO) Level}

Figure (11) shows that increasing the thermal efficiency decreases the level of CO. This is because of the better combustion of the fresh mixture and reduced amounts of fuel unburned.

\subsection{Effect on Nitric Oxide (NO) Level}

Figure (12) on the other hand shows an increase in the concentration of NO as the thermal efficiency is increased. This is because of the higher cylinder temperature, hence greater concentration of NO inside the cylinder. This, however, seizes as the thermal efficiency is increased beyond certain value. This is thought to be caused by the increased dissociation losses as the cylinder temperature is increased. 


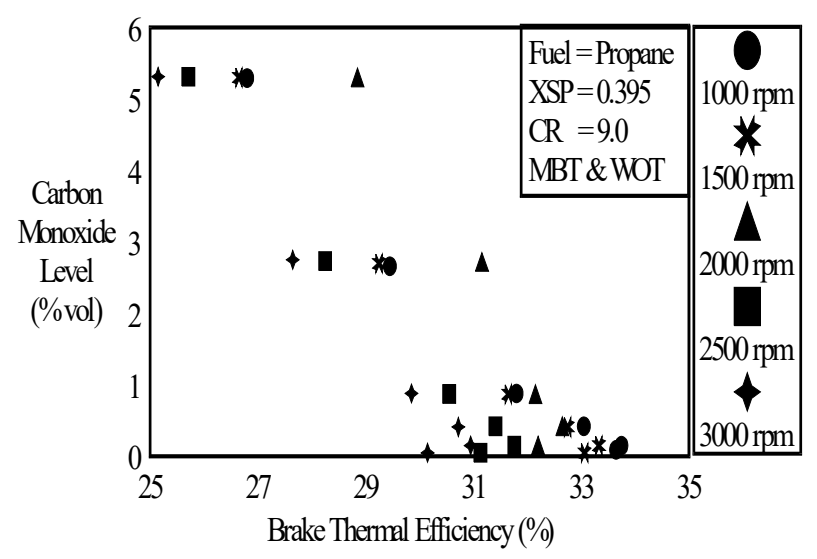

Figure 11. Effect of thermal efficiency on Carbon Monoxide level

Based on the above discussion, it becomes clear that the engine's fuel conversion efficiency has to be increased to achieve better performance with propane. The best way to achieve this is to optimize the engine design to suit the properties of propane. The result of the current attempt to optimize the engine design for propane in terms of its effect on thermal efficiency is shown in Figure (13).

This figure clearly shows the improvement of thermal efficiency in case of propane (shown in dark markers) with respect to those for gasoline (shown in empty markers). This improvement is clearer at higher speeds because of the increased in valve area that led to improve volumetric efficiency.

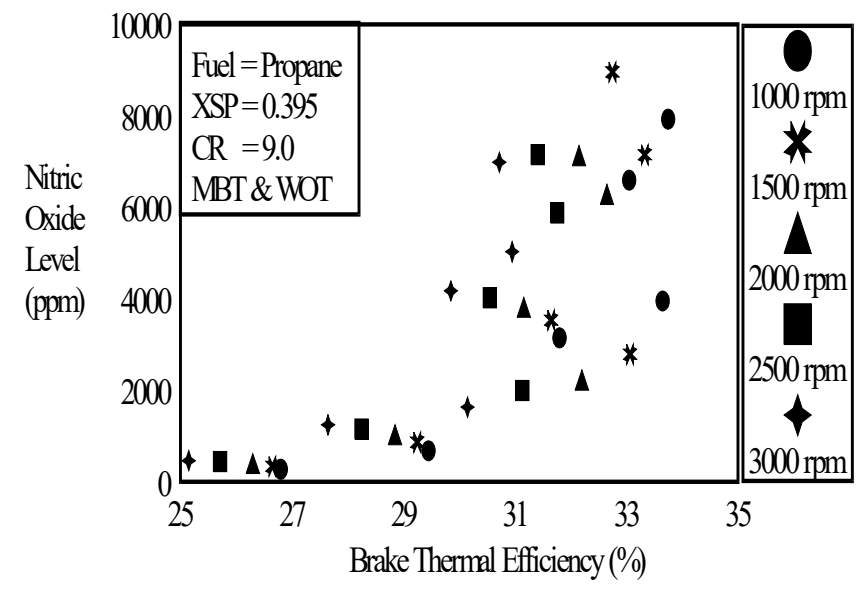

Figure 12. Effect of thermal efficiency on nitric oxide level

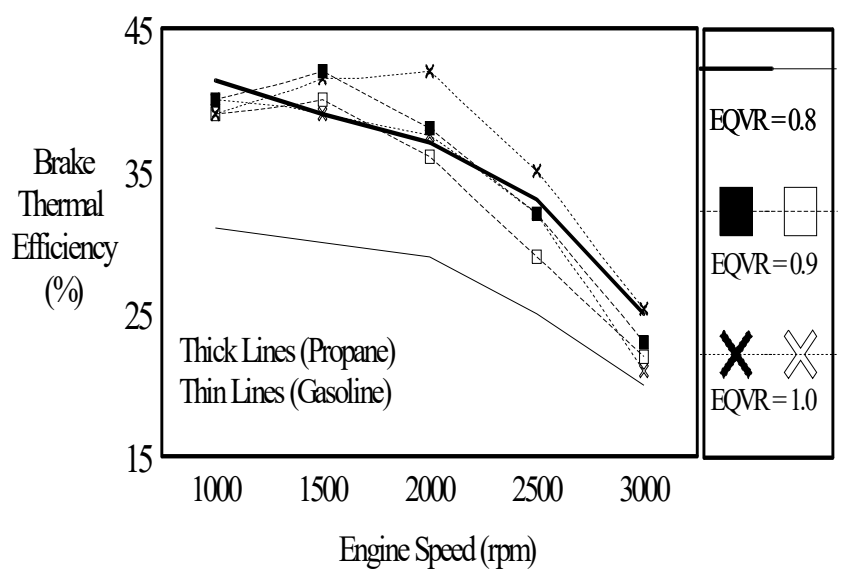

Figure 13. Comparison between ordinary and optimized engine 


\section{Conclusion}

1. A simulation program was developed to predict the performance of S.I. Engines using LPG (mainly propane) as fuel.

2. The effect of engine design and operating parameters on engine's brake thermal efficiency has been studied.

3. Increasing compression ratio, need for near central spark locations, larger valve areas and the run at leaner air-fuel equivalence ratios is shown to have a favorable effect on thermal efficiency.

4. Engine optimization for better thermal efficiency has been discussed.

5. The optimized engine showed increase in thermal efficiency compared to that for gasoline.

6. The presently developed computer model can be used to further optimize the engine for other parameters to achieve the best possible performance expected from propane.

\section{References}

Abd-Alla, T., Pucher, G. R., Bardon, M. F., \& Gardiner, D. P. (2003). Effects of spark characteristics on engine combustion with gasoline and propane. (No. 2003-01-3264). SAE Technical Paper. https://doi.org/10.4271/2003-01-3264

Annand, W. J. D. (1963). Heat transfer in the cylinders of reciprocating internal combustion engines. Proceedings of the Institution of Mechanical Engineers, 177(1), 973-996.

Annand, W. J. D. (1974). First Paper: Effects of Simplifying Kinetic Assumptions in Calculating Nitric Oxide Formation in Spark-Ignition Engines. Proceedings of the Institution of Mechanical Engineers, 188(1), 431-436.

Asada, Y.; and Okawa, N. (2002). Fuel controllers for LPG engines. Patent No. 2002155787, Type 20001122, Dated 2002-05-31.

Barkhordarioon, A., Moeini, M., and Pirzadeh, Y. (2001). Determination of the most suitable formulation of LPG as a vehicle fuel. Tahqiq-I Pizhuhishgah-I San'at-I Naft, 11(42), pp.14-25.

Bayraktar, H., \& Durgun, O. (2005). Investigating the effects of LPG on spark ignition engine combustion and performance. Energy Conversion and Management, 46(13), 2317-2333, https://doi.org/10.1016/j.enconman.2004.09.012

BENSON, I. B. R. (1983). Thermodynamics and Gas Dynamics of Internal Combustion Engines. Volume. J. Fluid Mech, 134, 45S469.

Benson, R. S., Annand, W. J. D., \& Baruah, P. C. (1975). A simulation model including intake and exhaust systems for a single cylinder four-stroke cycle spark ignition engine. International Journal of Mechanical Sciences, 17(2), 97-124. https://doi.org/10.1016/0020-7403(75)90002-8

Blizard, N. C., \& Keck, J. C. (1974). Experimental and theoretical investigation of turbulent burning model for internal combustion engines (No. 740191). SAE Technical Paper. https://doi.org/10.4271/740191

Branner, J., Kamel, M., Dunnuck, D., \& Mohan, J. (1999). The B5. 9 propane gas engine development. ASME-ICE (Experimental Studies in Engines and Natural Gas and Alternative Fuels), 2, 9-15.

Checkel, M. D., \& Dale, J. D. (1986). Computerized knock detection from engine pressure records. (No. 860028). SAE Technical Paper. https://doi.org/10.4271/860028

Daniel, W. A. (1967). Engine variable effects on exhaust hydrocarbon composition (a single-cylinder engine study with propane as the fuel) (No. 670124). SAE Technical Paper. https://doi.org/10.4271/670124

Deng B., L. (2003). Exhaust emissions from a small engine using gasoline, ethanol and LPG. Journal of Combustion Science and Technology, 9(3), 247-250.

Gupta, H. N., Bansal, B. B., \& Mohan, R. (1995). Computer Simulation of Power Cycle for Spark-Ignition Engines. Journal-Institution of Engineers India Part Mc Mechanical Engineering Division, 130-133.

Heywood, J.B., Internal Combustion Engine Fundamentals, McGraw Hill, Singapore, 1989.

Kapilan, N., Reddy, R. P., \& Mohanan, P. (2003, January). Studies on Esters of Coconut oil as Fuel for LPG-Biodiesel dual fuel engine. In ASME international mechanical engineering congress. Washington, DC (pp. 15-21). https://doi.org/10.1115/IMECE2003-42772 
Karim, G. A., and Wierzba, I. (1983). Comparative studies of methane and propane as fuels for spark ignition and compression ignition engines. (No. 831196). SAE Technical Paper. https://doi.org/10.4271/831196

Kim, I., Lee, D., and Goto, S. (1997). Combustion process modeling using a mechanism in an LPG lean burn SI engine. SAE Paper, 970899. https://doi.org/10.4271/1999-01-3481

Komota, T.; and Inoue, T. (2005). Fuel injection device for liquefied gas engine. Patent No. JP-2005042584, Type A2, dated 2005-02-17.

Li, X. G., Wang, Y. Y., He, Q. L., \& Zhang, A. G. (2012). Experimental Study on the EFI Engine Fueled with LPG. In Advanced Materials Research (Vol. 366, pp. 264-267). Trans Tech Publications. https://doi.org/10.4028/www.scientific.net/AMR.366.264.

Liu, W., Liu, S. J., Kuang, X., \& Sun, J. (2013). LPG/Gasoline Dual-fuel engine Design and investigation about its performance. In Applied Mechanics and Materials (Vol. 333, pp. 2025-2029). Trans Tech Publications. https://doi.org/10.4028/www.scientific.net/AMM.333-335.2025.

Ozcan, H. and Yamin, J.A., (2008). Performance and emission characteristics of LPG powered four stroke SI engine under variable stroke length and compression ratio. Energy Conversion and Management, 49(5), pp.1193-1201. https://doi.org/10.1016/j.enconman.2007.09.004

Price, P., Guo, S., and Hirschmann, M. (2004). Performance of an evaporator for a LPG powered vehicle. Applied Thermal Engineering, 24(8), 1179-1194. https://doi.org/10.1016/j.applthermaleng.2003.11.028

Sun,L.; Zhang, J.; and Shen, B. (2002). Application of LPG to carburetor engine. Huanjing Wuran Yu Fangzhi, 24(3), pp. 154-156.

Takeda, M.; and Matsubara, Y. (1997). Development of a new LPG engine for commercial vehicle (3 truck). Jidoshi Gitutsu, 51(1), pp. 67-72.

Tsuruya, K.; Taniguchi, S.; Tsukazaki, Y. (2004). Method for controlling the fuel injection and ignition timing of LPG-fueled engine. Patent No. 2004324509, Type A2, Dated 2004-11-18.

Wallace, S. J. (1989). Assessment of "First Generation" Propane Conversion Equipment. SAE NO. 892133. https://doi.org/10.4271/892144.

Wang, H.; and Bian, Y. (2005). Experimental study on dimethyl ether-LPG blends. Xiaoxing Neiranji Yu Motuoche, 34(4), pp.29-32.

Wang, Z.; Wang, Z.; and zhang, Q. (2001). Analysis of LPG fuel engine combustion model based on thermodynamics model. Jixie Gongcheng Xuebao, 37(6), pp. 82-85.

Winterbone, D. and Turan, A., (2015). Advanced thermodynamics for engineers. Butterworth-Heinemann.

Woo, Y., Yeom, K., Bae, C., Oh, S., and Kang, K. (2004). Effects of stratified EGR on the performance of a liquid phase LPG injection engine. SAE paper no: 2004-01-0982. https://doi.org/10.4271/2004-01-0982.

Yamin, J. A., Gupta, H. N., \& Bansal, B. B. (1999). Analytical Study of the Effect of Spark Plug Location on the Performance of an Engine using Propane and Gasoline as Fuels. Journal-Institution of Engineers India Part Mc Mechanical Engineering Division, 90-94.

Yamin, J.A. and Ozcan, H., (2011). Second-law analysis of an LPG-powered 4-stroke SI engine under variable stroke length and compression ratio. International Journal of Exergy, 8(2), 113-127. https://doi.org/10.1504/IJEX.2011.038514

Yamin, J.A., and Badran, O.O. (2002). Analytical study to minimize the heat losses from a propane powered 4-stroke spark ignition engine. Renewable Energy, 27(3), 463-478. https://doi.org/10.1016/S0960-1481(02)00008-3

Yamin, J.A., Gupta, H.N. and Bansal, B.B. (2003). The effect of combustion duration on the performance and emission characteristics of propane-fueled 4-stroke si engines. Emirates Journal for Engineering Research, $8(1), 1-14$.

\section{APPENDIX (A)}

Brief Description of the Model.

The combustion chamber was generally divided into burned and unburned zones separated by a flame front (figure A-1). The first law of thermodynamic, equation of state and conservation of mass and volume were 
applied to the burned and unburned zones. The pressure was assumed to be uniform throughout the cylinder charge. A system of first order ordinary differential equations were obtained for the pressure, mass, volume, temperature of the burned and unburned zones, heat transfer from burned and unburned zone, and mass flow into and out of crevices.

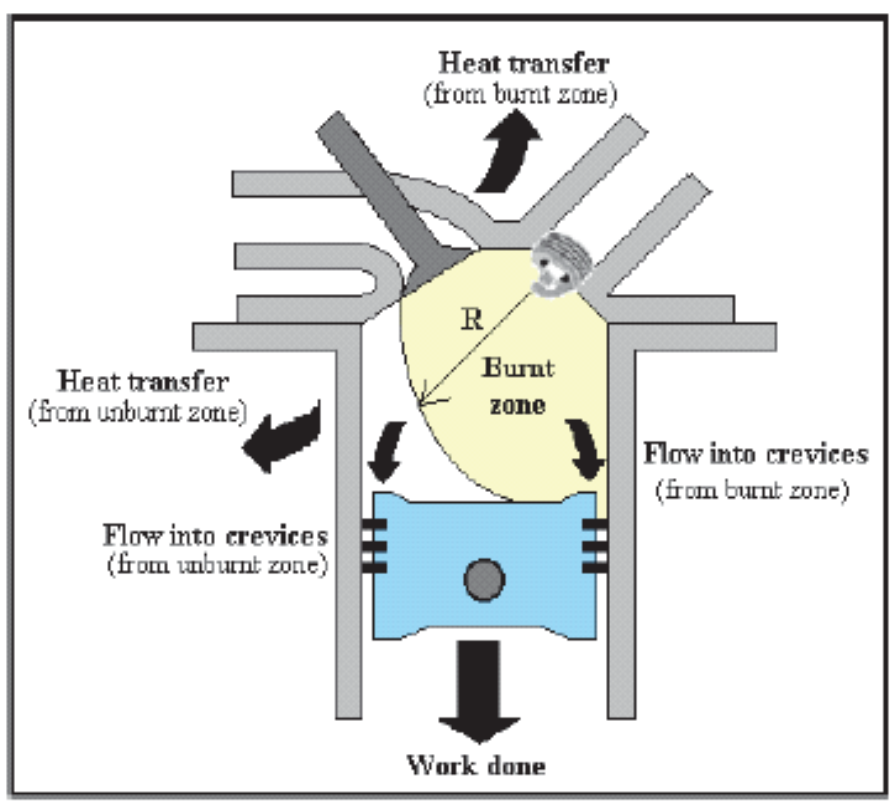

Figure (A-1). Two zone thermodynamic model for combustion

\section{Compression}

The following assumptions have been made during the calculations of compression stroke: (1) The mixing between fresh charge and residual gases is perfect, (2) No chemical reaction occurs during compression.

In a conventional spark ignition engine the fuel and air are mixed together in the intake system, inducted through the intake valve into the cylinder, where mixing with residual gas takes place, and then compressed. Under normal operating conditions, combustion is initiated towards the end of the compression stroke at the spark plug by an electric discharge. Following inflammation, a turbulent flame develops, propagates through this essentially premixed fuel, air, burned gas mixture until it reaches the combustion chamber walls, and then extinguishes to begin expansion stroke until the exhaust valve opening. Each of these processes is discussed below to complete engine power cycle simulation. The compression process starts at the trapped condition, and ends after delay period process, when the mixture is ignited by the spark plug. The state of the gas during this stage is derived by using a perfect mixing model for fresh charge and residuals from the previous cycle.

The calculation procedure starts with the trapped mass of fuel, air and residuals. The pressures and temperatures in this stroke are then calculated using the first law of thermodynamics equations and the equation of state:

$$
\begin{gathered}
\frac{d p}{d \theta}=\left\{\frac{R}{C_{V}}\left(\frac{d Q}{d \theta}\right)-p \frac{d V}{d \theta}\left(\frac{R}{C_{V}}+1\right)\right\} / V \\
\frac{d T_{u}}{d \theta}=T_{u}\left(\frac{1}{V} \cdot \frac{d V}{d \theta}+\frac{1}{p} \cdot \frac{d p}{d \theta}\right) \\
\frac{d W}{d \theta}=p \frac{d V}{d \theta}
\end{gathered}
$$

This continues till the nominal spark time, when combustion period is said to commence. The heat transfer rate from the gas to wall is calculated using Annand's equation (Yamin et.al, 1999 and Annand, 1963) for convective heat transfer: 


$$
\left.\frac{\mathrm{Q}}{\mathrm{A}_{\mathrm{p}}}=\frac{\mathrm{ak} \mathrm{q}}{\mathrm{D}}\left(\mathrm{R}_{\mathrm{e}}\right) \mathrm{b}_{\mathrm{u}}-\mathrm{T}_{\mathrm{w}}\right)
$$

where $\quad \mathrm{K}_{\mathrm{q}}=\frac{\mathrm{C}_{\mathrm{p}} \mu}{0.7}$

The variables are continuously updated during calculation using the general formula:

$$
\mathrm{x}_{\mathrm{n}+1}=\mathrm{x}_{\mathrm{n}}+\frac{\mathrm{dx}}{\mathrm{d} \theta} \Delta \theta
$$

where " $x$ " is the variable. The numerical procedure used for this purpose is the Runge-Kutta method.

\section{Ignition}

The numerical method used for this purpose is the Runge-Kutta method. After spark occurrence, the delay period is calculated using the following equation (Gupta et.al, 1995);

$$
(\Delta \theta)_{\text {Delay }}=\left(\frac{360 * \mathrm{~N}}{\mathrm{U}_{\mathrm{t}}}\right)\left(\frac{0.0015 * \mathrm{~V}}{\pi}\right)^{\frac{1}{3}}
$$

During this period the mixture is considered to be unburned and the compression process is continued. The process continues for as many time intervals as necessary until the total angle from the nominal spark timing is greater than delay period. The combustion process is said to have commenced, and is divided into two stages. The first stage is ignition and initiation of two zones in combustion space and the second stage is flame front propagation.

After the combustion of the small nucleus of fuel-air mixture the combustion chamber is subdivided into two zones, a burned zone, suffix (b), and an unburned zone, suffix (u).

\section{Species Formation}

It is assumed that only 12 species are present in the combustion products both inside the cylinder as well as the exhaust. These are: $\mathrm{H}_{2} \mathrm{O}, \mathrm{H}_{2}, \mathrm{OH}, \mathrm{H}, \mathrm{N}_{2}, \mathrm{NO}, \mathrm{CO}_{2}, \mathrm{CO}, \mathrm{O}_{2}, \mathrm{O}$ and $\mathrm{A}$. The governing equations for the mechanism of NO formation are (based on Lavoie's proposed model ((Winterbone, 2015)

$$
\begin{aligned}
& \text { (1) } \mathrm{N}+\mathrm{NO} \Leftrightarrow \mathrm{N}_{2}+\mathrm{O} \quad K_{f 1}=3.1 * 10^{10 * E^{(-160 / T)} \quad \mathrm{m}^{3} / \mathrm{kmols}} \\
& \text { (2) } \mathrm{N}+\mathrm{O}_{2} \Leftrightarrow \mathrm{NO}+\mathrm{O} \quad K_{f 2}=6.4 * 10^{6} * T^{*} E^{(-3125 / T)} \mathrm{m}^{3} / \mathrm{kmols} \\
& \text { (3) } \mathrm{N}+\mathrm{OH} \Leftrightarrow \mathrm{NO}+\mathrm{H} \quad K_{f 3}=4.2 * 10^{10} \mathrm{~m}^{3} / \mathrm{kmols} \\
& \text { (4) } \mathrm{H}+\mathrm{N}_{2} \mathrm{O} \Leftrightarrow \mathrm{N}_{2}+\mathrm{OH} \\
& K_{f 4}=3.0^{*} 10^{10 * E^{(-5350 / T)}} \\
& \text { (5) } \mathrm{O}+\mathrm{N}_{2} \mathrm{O} \Leftrightarrow \mathrm{N}_{2}+\mathrm{O}_{2} \\
& K_{f 5}=3.2 * 10^{12 *} E^{(-18900 / T)} \\
& \begin{array}{l}
\mathrm{m}^{3} / \mathrm{kmols} \\
\mathrm{m}^{3} / \mathrm{kmols}
\end{array} \\
& \text { (6) } \mathrm{O}+\mathrm{N}_{2} \mathrm{O} \Leftrightarrow \mathrm{NO}+\mathrm{NO} \quad K_{f 6}=K_{f 5} \\
& \text { (7) } \mathrm{N}_{2} \mathrm{O}+\mathrm{M} \Leftrightarrow \mathrm{N}_{2}+\mathrm{O}+\mathrm{M} \quad K_{f 7}=10^{12 *} E^{(-30500 / T)} \\
& \mathrm{m}^{3} / \mathrm{kmols}
\end{aligned}
$$

In these equations the rate constants $\left(\mathrm{K}_{\mathrm{fi}}\right)$ are all in $\mathrm{m}^{3} / \mathrm{kmols}$. $\mathrm{M}$ is a third body which may be involved in the reactions, but is assumed to be unchanged by the reactions. "M" can be assumed to be $\mathrm{N}_{2}$. These equations can be applied to the zone containing "burned" products, which exists after the passage of the flame through the unburned mixture. It will be assumed that $\mathrm{H}$ and $\mathrm{OH}$, and $\mathrm{O}$ and $\mathrm{O}_{2}$ are in equilibrium with each other; these values can be calculated by the methods described in (Annand, 1974).

These values can be used to give the rate of formation of (NO) as :

$$
\left.\frac{1}{\mathrm{~V}} \cdot \frac{\mathrm{d}}{\mathrm{dt}}[\mathrm{NO}] \cdot \mathrm{V}\right]=2 .\left(1-\alpha^{2}\right)\left[\frac{\mathrm{R}_{1}}{1+\alpha \frac{\mathrm{R}_{1}}{\mathrm{R}_{2}+\mathrm{R}_{3}}}+\frac{\mathrm{R}_{6}}{1+\frac{\mathrm{R}_{6}}{\mathrm{R}_{4}+\mathrm{R}_{5}+\mathrm{R}_{7}}}\right]
$$

Where $\beta=\frac{\mathrm{R}_{1}+\alpha\left(\mathrm{R}_{2}+\mathrm{R}_{3}\right)}{\left(\alpha \mathrm{R}_{1}+\mathrm{R}_{2}+\mathrm{R}_{3}\right)} \quad$ and $\quad \gamma=\frac{\mathrm{R}_{4}+\mathrm{R}_{5}+\alpha^{2} \mathrm{R}_{6}+\mathrm{R}_{7}}{\left(\mathrm{R}_{4}+\mathrm{R}_{5}+\mathrm{R}_{6}+\mathrm{R}_{7}\right)}$ 
The detailed method is given in reference (Winterbone, 2015).

\section{Copyrights}

Copyright for this article is retained by the author(s), with first publication rights granted to the journal.

This is an open-access article distributed under the terms and conditions of the Creative Commons Attribution license (http://creativecommons.org/licenses/by/4.0/). 